\title{
Laryngotracheal giant cell tumor: case report and literature review
}

\author{
Mark S Swanson, Tamara N Brown \\ Department of Otolaryngology, Keck School of Medicine of University of Southern California, Los Angeles, United States \\ Correspondence: Mark Swanson. Address: Department of Otolaryngology, General Hospital, Los Angeles, United States. \\ E-mail: mark.swanson@med.usc.edu
}

Received: October 12, 2014

Accepted: November 27, 2014 Online Published: December 08, 2014

DOI : $10.5430 / c r c p . v 2 n 2 p 12$

URL: http://dx.doi.org/10.5430/crcp.v2n2p12

\section{Abstract}

Giant cell tumor is a benign but locally aggressive tumor typically found in the long bones but has also been reported in several head and neck locations. Although rare, it can arise from endochondral bone within the larynx, however there have been no prior reported occurrences in the trachea. We report a giant cell tumor of the cricoid cartilage presenting as an endotracheal mass with dysphonia and dyspnea on exertion which was treated with endoscopic excision. The tumor is diagnosed histologically as no clinical or radiographic findings are specific for giant cell tumor. Optimal treatment and recurrence rate is unknown but review of laryngeal lesions suggests complete excision has favorable results. Radiation therapy poses risk for malignant transformation.

\section{Key words}

Giant cell tumor, Tracheal neoplasm, Giant cell tumor of the larynx, Giant cell tumor of the trachea

\section{Introduction}

Giant cell tumor (GCT) is an uncommon tumor that typically affects the long bones but has been reported to occur in the head and neck in the sinonasal cavities, mandible, skull base, soft tissue, and vertebral bodies ${ }^{[1-9]}$. Although rare, there are reported cases of GCT of the larynx, however a PubMed search failed to show any reports of this tumor within the tracheal lumen. Herein we report a case of GCT arising from the cricoid cartilage presenting as a mass within the trachea.

\section{Case report}

A 76-year-old Hispanic female presented from the Emergency Department with progressive dyspnea and breathy dysphonia. Three months prior to presentation, she had sudden onset of breathy dysphonia which wax-and-waned, but her symptoms have become more pronounced recently. At the time of presentation, she began to have exertional dyspnea and difficulty laying supine that had slowly progressed. At a prior ED visit she was given an albuterol inhaler and oral antibiotics without relief. A return presentation to the ED with persistence of symptoms prompted a CT of the neck (see Figure 1) demonstrating a $1 \mathrm{~cm}$ soft tissue mass pedicled to the anterior cricoid cartilage. She denies inciting trauma, infection, fevers, wt loss, dysphagia, or hemoptysis. She has a history of hypertension, hyperlipidemia, and well controlled type II diabetes but denied tobacco or alcohol use. 

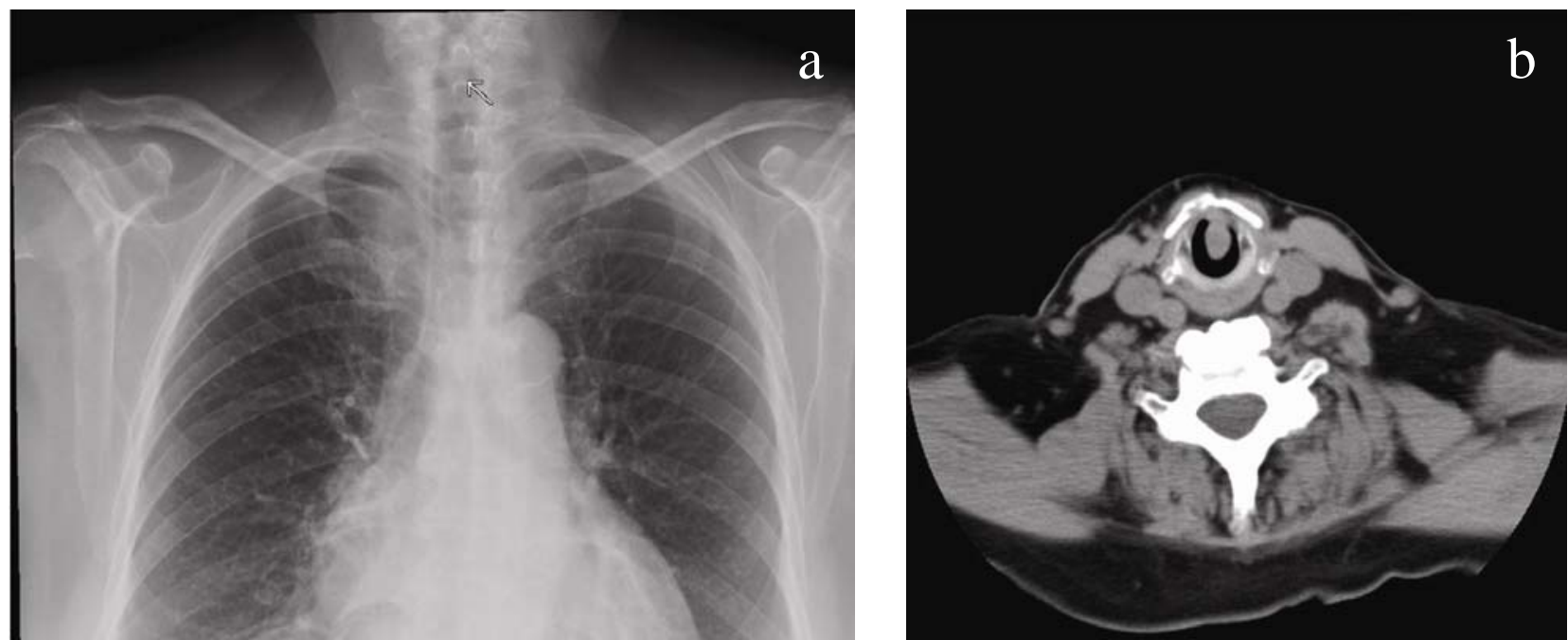

Figure 1. CXR (a), axial CT neck (b) and coronal CT neck (c) with contrast showing the anteriorly pedicled soft tissue mass arising from the cricoid cartilage.

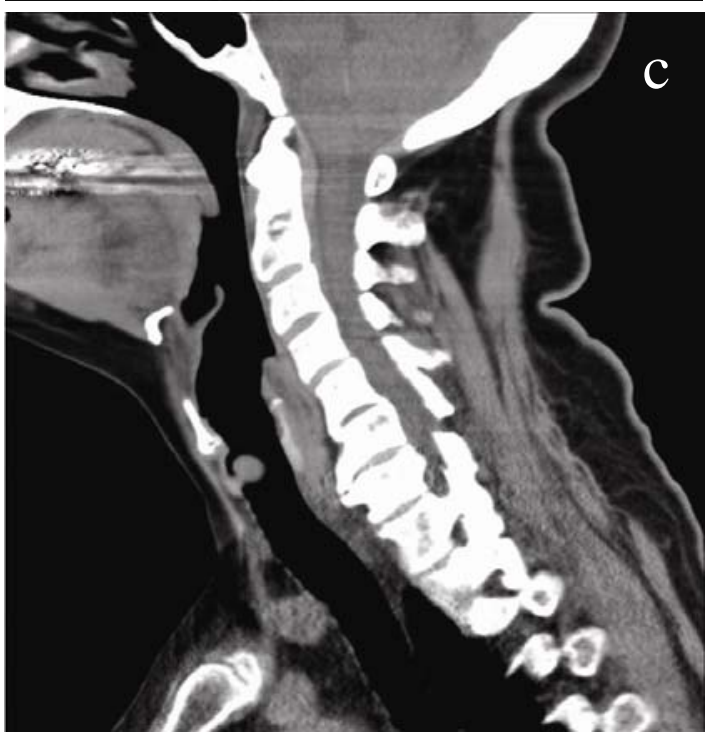

At this time, she was evaluated by an otolaryngologist and found to have mild biphasic stridor on exertion without respiratory distress. She had no palpable neck masses and normal external laryngeal and tracheal landmarks. Flexible fiberoptic examination confirmed an exophytic mass inferior to the glottis which had slight elevation and depression with respirations. This mass abutted the inferior aspect of the true vocal folds preventing complete glottic closure, however both vocal folds were mobile.

The patient was taken to the operating room where direct laryngoscopy with endoscopic mass excision was performed. With spontaneous respirations maintained, the laryngoscope was introduced and placed in suspension. The patient was then intubated and the mass was retracted while using sharp dissection with microscissors to remove the lesion with a small cuff of normal mucosa. The patient was extubated and awakened with resolution of her stridor. Permanent section of the resected mass was consistent with a giant cell tumor of the trachea (see Figure 2).

The patient was seen in clinic one week later with complete resolution of dyspnea and dysphonia. Repeat fiberoptic examination demonstrated well mucosalized surgical bed without evidence of recurrent or residual tumor. She was seen again four months post-operatively with mild hoarseness but otherwise asymptomatic. At that time an awake transnasal tracheoscopy was performed without evidence of recurrence (see Figure 3). At 10 months post-operatively, the patient developed a small erythematous nodule in the anterior subglottis that is asymptomatic and has been stable for three months and is being managed with observation. 

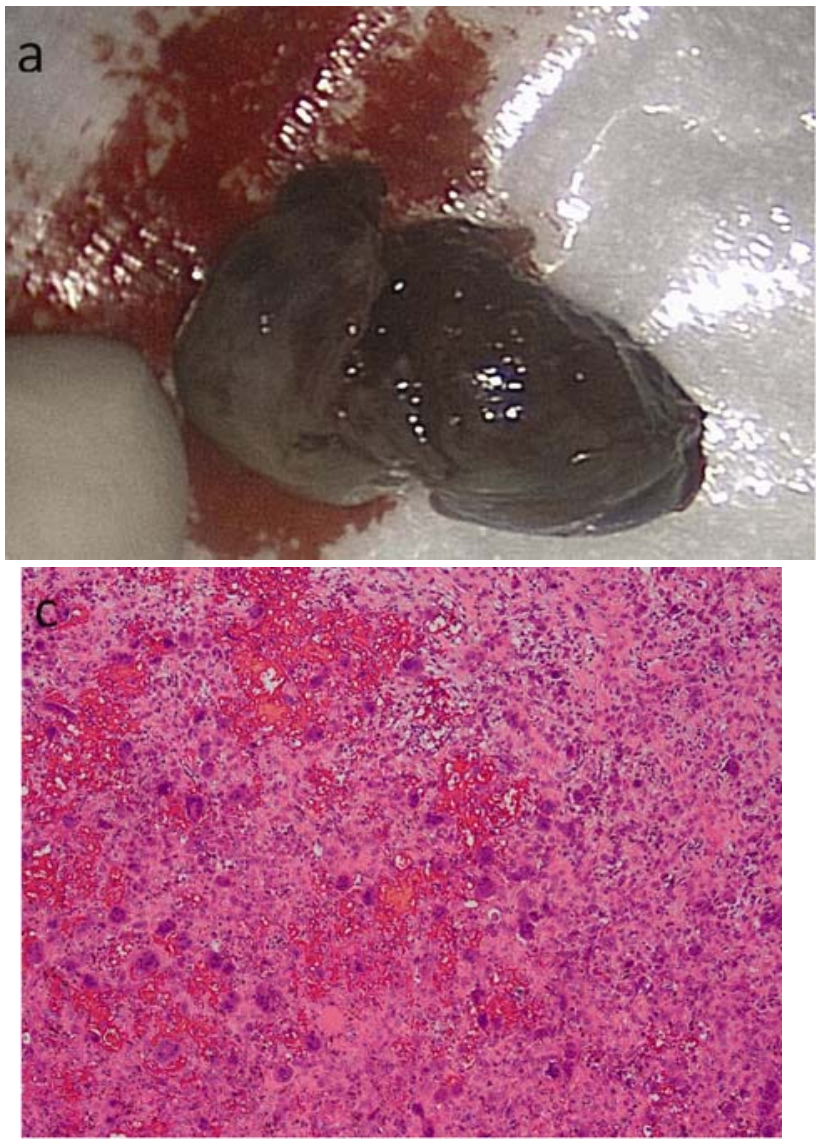
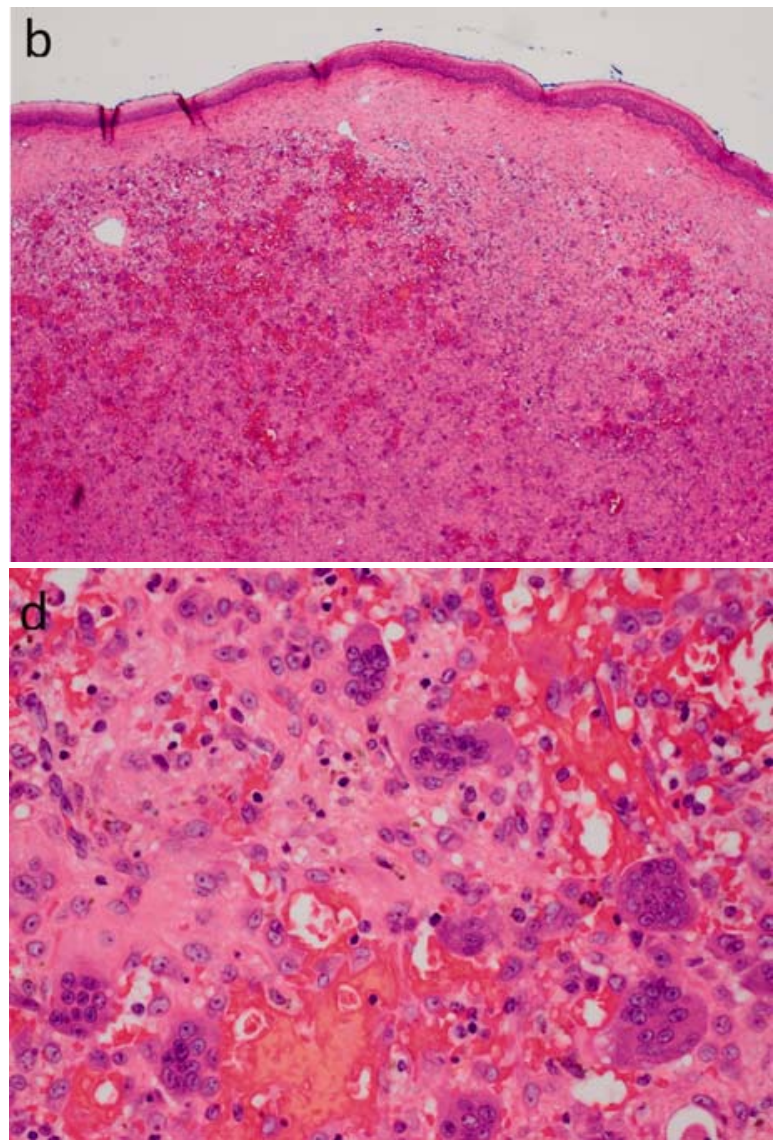

Figure 2. (a). The post-resection gross appearance of the specimen; (b). Permanent sections showing histology of tracheal giant cell tumor under low; (c). medium; (d). high power. Note the presence of normal squamous epithelium, evenly distributed multinucleated giant cells, and homogenous stromal cells.

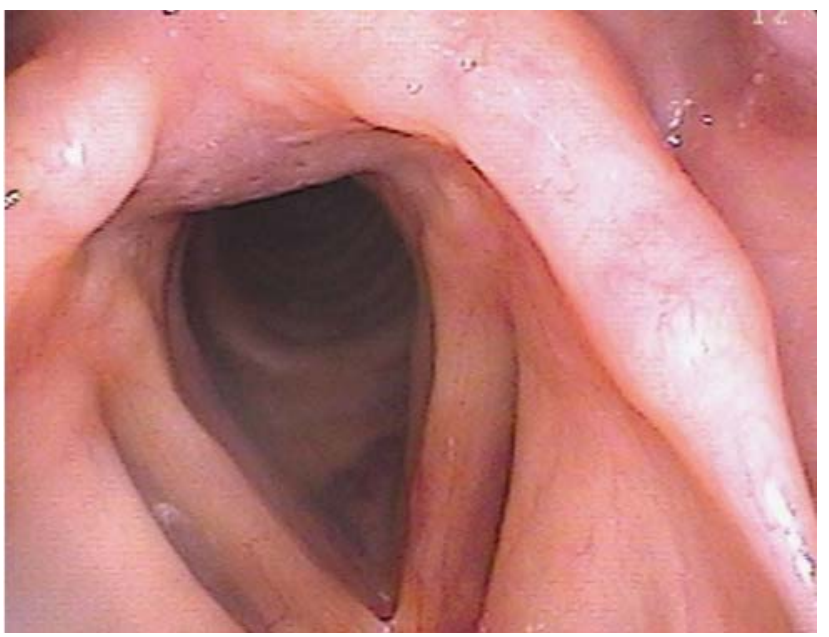

Figure 3. Laryngoscopy and tracheoscopy is performed four months postoperatively without evidence of recurrence.

\section{Discussion}

Since stridor appears as a late sign, a tracheal mass must be considered for dyspnea, cough, wheezing, or hemoptysis unresponsive to antibiotics, bronchodilators, or corticosteroids. These symptoms are often misdiagnosed as asthma, 
COPD, or infection, and evaluation with chest $\mathrm{x}$-ray is likely to miss a tracheal mass. Routine chest $\mathrm{x}$-ray is $25 \%-50 \%$ sensitive for these masses, so they are best evaluated with direct visualization and $\mathrm{CT}^{[10]}$.

On imaging, a well circumscribed pedunculated tracheal mass most likely represents a benign process such as fibroma, hemangioma, hamartoma, inflammatory mass, or papilloma, however malignancy should also be considered. Malignant lesions are most commonly squamous cell carcinoma or adenoid cystic carcinoma, but can also be mucoepidermoid carcinoma, chondrosarcoma, or a carcinoid tumor.

Giant cell tumor is a rare tumor of bony origin characterized multinucleated giant cells resembling osteoclasts. It is typically found in long bones of the distal femur, proximal tibia, and distal radius, but has been described in the head and neck as well. Of note, there is a correlation with pre-existing Paget's disease and involvement of the mandible or vertebral column ${ }^{[11]}$. Grossly, the lesion appears as a homogenous tan moderately firm mass with focal areas of hemorrhage or necrosis. Histologically, GCT has a background of homogenous mononuclear stromal cells with evenly dispersed multinucleated giant cells. The stromal cells may produce an osteoid matrix with osteoblastic rimming and take on a spindle or ovoid morphology. On immunohistochemistry, proliferating nuclear antigen is positive in the stromal cells, but not giant cells. Conversely, CD68 and PTH-LP was found in the osteoclast-like giant cells, but not typically in the stromal cells. Mononuclear stromal cells are considered neoplastic, but whether giant cells and histiocytic stromal cells are reactive or neoplastic is undetermined. It is thought that the proliferation of mononuclear histiocytic stromal cells and osteoclast-like giant cells are stimulated in an autocrine fashion from cytokines ${ }^{[12]}$. GCT can be distinguished from reparative giant cell granuloma based on its uniformity of giant cell distribution and lack of inflammatory cells. Brown tumor of hyperparathyroidism is also on the histologic differential diagnosis but can be excluded in the presence of normal serum calcium and phosphate ${ }^{[11]}$.

With 30 reported cases in the literature, GCT rarely can arise within the laryngeal framework and is presumed to be from bony foci within the thyroid cartilage, cricoid cartilage, or epiglottis ${ }^{[8]}$. In the larynx, the tumor is locally aggressive but without potential to metastasize. Reported treatment is for complete excision with a cuff of normal tissue, typically with a partial or total laryngectomy, as curettage alone in long bone lesions has a $50 \%$ local recurrence rate ${ }^{[11,13]}$. Excision is preferred over radiation therapy due to risk of malignant degeneration with reports as high as $25 \%$ in the orthopedic literature ${ }^{[14]}$.

Malignant GCTs are typically radiation induced and account for $10 \%$ of GCT. A five year survival rate of $32 \%$ has been reported with pulmonary metastasis being most common site of distant metastasis. De novo malignant GCT is less common ${ }^{[11,13,15]}$. Malignancy is characterized by focal anaplastic pleomorphic tumor cells with atypical nuclear features in the presence of identifiable GCT characteristics. Vascular invasion, soft tissue extension, and high mitotic index are not sufficient to diagnose malignant GCT ${ }^{[11]}$.

\section{Conclusion}

Giant cell tumor is a rare clinical entity in the head and neck with case reports of lesions arising within endochondral bone in the laryngeal framework, but no prior reported cases arising within the trachea. Optimal treatment and recurrence rates are unknown but lesions within the larynx have reported favorable outcomes for total but conservative excision. Radiation therapy is less ideal given risk of malignant transformation.

\section{References}

[1] Hamlin WB, Lund PK. Giant cell tumors of the mandible and facial bones. Arch Otolaryngol. 1967; 86: 658-65. http://dx.doi.org/10.1001/archotol.1967.00760050660011

[2] Lee HJ, Lum C. Giant-cell tumor of the skull base. Neuroradiology. 1999; 41: 305-7. http://dx.doi.org/10.1007/s002340050753 
[3] Wang Y, Honda K, Suzuki S, et al. Giant cell tumor at the lateral skull base. Am J Otolaryngol. 2006; 27: 64-7. http://dx.doi.org/10.1016/j.amjoto.2005.05.021

[4] Saleh EA, Taibah AK, Naguib M, et al. Giant cell tumor of the lateral skull base: a case report. Otolaryngology Head Neck Surg. 1994; 111: 314-8. http://dx.doi.org/10.1016/S0194-5998(94)70608-5

[5] Chan J, Gannon FH, Thompson LD. Malignant giant cell tumor of the sphenoid. Ann Diagn Pathol. 2003; $7: 100-5$. http://dx.doi.org/10.1053/adpa.2003.50020

[6] Gille O, Soderlund C, Berge J, et al. Triple total cervical vertebrectomy for a giant cell tumor: case report. Spine. 2005; 30: E272-5. http://dx.doi.org/10.1097/01.brs.0000162931.80082.04

[7] Laothamatas J, et al. Extraskeletal giant cell tumor of the larynx: case report and review fo the literature. Ear, Nose and Throat Journal. 2011; 90(5): p226. PMid:21563092.

[8] Koji Nishimura, MD, et al. Giant cell tumor of the larynx: a case report and review of the literature. American journal of Otolaryngology. 2007; 28: 436-440. http://dx.doi.org/10.1016/j.amjoto.2006.11.008

[9] Zheng-Ping Shi, Jih-Chin Lee, et al. Giant cell tumor of the larynx. Otolaryngology-Head and Neck Surgery. 2008; $138: 117-118$. http://dx.doi.org/10.1016/j.otohns.2007.10.006

[10] Xu LT, Sun ZF, Li ZJ, Wu LH, Zhang ZY, Yu XQ. Clinical and pathologic characteristics in patients with tracheobronchial tumor: report of 50 patients. Ann thoracic Surg. 1987; 43: 276-278. http://dx.doi.org/10.1016/S0003-4975(10)60611-X

[11] Bullough PG. Benign non-matrix-producing bone tumors. Orthopaedic Pathology, Fifth Edition. Mosby Inc. 2010 ; $19: 49-476$.

[12] Masui F, Ushigome S, Fujii K. Giant cell tumor of bone: an immunohistochemical comparative study. Pathol Int. 1998; 48(5): 355-61. http://dx.doi.org/10.1111/j.1440-1827.1998.tb03918.x

[13] Armstrong WB, Vokes DE, Maisel RH. Malignant tumors of the larynx. Cummings Otolaryngology: Head \& Neck surgery. 5th edition. 107: 1482-1511.

[14] Chen ZX, Gu DZ, Yu ZH, et al. Radiation therapy of giant cell tumor of bone: analysis of 35 patients. Int J Radiat Oncol Biol Phys. 1986; 12: 329-34. http://dx.doi.org/10.1016/0360-3016(86)90346-9

[15] Day TA, Buchmann L, et al. Neoplasms of the Neck. Cummings Otolaryngology: Head \& Neck surgery. 5th edition. 118: 1657-1672. 